\title{
JUSTIFICATION OF SELECTION OF MEANS AND METHODS OF THE ORAL CAVITY HYGIENE IN CHILDREN WITH CYSTIC FIBROSIS
}

\author{
Rosana Nazaryan \\ Department of Pediatric Dentistry and Implantology ${ }^{1}$ \\ rosnazaryan@gmail.com \\ Maryna Tkachenko \\ Department of Pediatric Dentistry and Implantology ${ }^{1}$ \\ tmvv.13@gmail.com \\ Oksana Piontkovska \\ Department of Obstetrics, Gynecology and Pediatric Gynecology ${ }^{1}$ \\ hr_odkb1@i.ua \\ ${ }^{1}$ Kharkiv National Medical University \\ 4 Nauky ave., Kharkiv, Ukraine, 61022
}

\section{Abstract}

Cystic fibrosis (CF) promotes the development of gingivitis in children.

The high prevalence and early manifestation of gingivitis is due to a combination of many factors. The pathogenic mechanisms of cystic fibrosis lead to disruption of normal physiological processes in the oral cavity, in particular, to a decrease in the level of salivation, to an increase in the viscosity of saliva, to a suppression of local immunity. Therefore, poor oral hygiene contributes to oral diseases.

The aim of the study was to determine the level of oral hygiene in children with CF as one of the reasons for the development of gingivitis, and to select dental hygiene products that active towards factors that affect plaque.

Material and methods. A total of 24 children with CF in the Ukrainian population participated in the study. The hygienic index OHI-S (J. C. Green, J. R. Wermillion, 1964) was calculated. The data were analyzed using Student's criterions. The analysis was performed with a confidence level of $95 \%$.

Results. The level of hygiene of the oral cavity was unsatisfactory among patients (OHI-S=2.19 \pm 0.11 ). Hygiene methods and dental hygiene products, to taking into account the manifestation of the pathogenesis of somatic disease, were selected. A follow-up study after 3 months revealed a significant positive trend in indicators of oral hygiene.

Conclusions. This study has shown the low level of oral hygiene in children with CF. Hygienic education and motivation of these patients could help them achieve a higher level of oral health knowledge and are important starting points for the treatment and prevention of gingivitis. There was a significant improvement of the oral hygiene level after training children and after the proper selection of hygiene products. The dentists should use means and methods that have not contraindicate in patients of this category. It is recommended to monitore the hygiene indices to establish the effectiveness of the measures and necessity for individually therapy correction.

Keywords: children, cystic fibrosis, dental plaque, oral hygiene.

DOI: $10.21303 / 2504-5679.2020 .001350$

\section{Introduction}

To date, the impact of $\mathrm{CF}$ on the development of gingivitis in children has been known. It was proved that microbial colonization of the oral cavity and dental plaque are the main factors of caries and periodontal disease. Peculiarities of the pathogenesis of CF probably contribute to the implementation by microorganisms of their pathogenic potential. It heretofore was investigated that microbiocinosis of plaque in children with $\mathrm{CF}$ is characterized by active colonization of enamel of teeth by $\alpha$-hemolytic streptococci, which form associations with gram-positive or gram-negative bacteria and fungi $C$. albicans. Wherein the age of the child and the composition of the microbiota of the respiratory system affect the characteristics of the microflora of the plaque [1]. 
The volume of plaque increases and biofilm forms change in conditions of insufficient oral hygiene. The replacement of microorganisms and the emergence of similar species with strong pathogenic properties occur. Microorganisms produce acids, endotoxins, lysosomal enzymes, that destroy the enamel and cells of periodontal tissues [2, 3]. Inflammatory processes of gums in patients with CF begin in conditions of low salivation, changes in rheological properties of the oral fluid, with a decrease of the factors of local immunity $[4,5]$.

Different factors could affect the formation and quality of the plaque in children with CF [6]. Usually it is a chronic colonization of pathogenic microflora among these patients. Anatomically determined a transition of microflora from the lungs to the oral cavity, in particular, Ps. Aerugino$s a$, that quickly attaches to the surfaces and proliferates $[2,7]$.

The content of the immune defence factors in the oral fluid decreases with insufficient secretion of saliva. The amount of immunoglobulins, lysozyme and proteins that have adhesive properties and have involved in antimicrobial protection, is not sufficient to evacuate bacteria. At the same time, conditions for bacterial adhesion and the association of microorganisms disimprove the microbiocenosis and the properties of the biotope of the oral cavity [8,9].

An increase of the concentration of electrolytes in mixed saliva is present at CF. The formation of dental pellicle and protein depletion accelerate if low values of the $\mathrm{pH}$ of the oral liquid and in the presence of calcium and phosphorus ions. These microelements also reinforce the adhesion of proteins to hydroxyapatite of enamel $[10,11]$.

Patients receive regularly inhalations with corticosteroids and other medicaments as a treatment of CF that leads to violations of normal physiological processes in the oral cavity, including immunosuppressive action. Moreover, this increases the frequency of colonization of bacteria. In addition, the part of the hormonal drug deposits in the organism and oral cavity and on the dental plaque [12-14].

A diet with high-energy value is necessary for patients with CF. They must compensate energy necessity with carbohydrates, protein and fats $[15,16]$. At the same time, an excess of carbohydrates in the diet leads to an increase in the activity of enzymes of the microflora and to the producing of organic acids. These are cariogenic and periodontopathogenic factors in the context of unsatisfactory oral hygiene and immune disturbance [17, 18].

Since microflora of the oral cavity is the main initiator of pathogenicity factors, removal of the dental plaque should be the first stage of dental rehabilitation [19, 20].

The formation of general knowledge and skills of oral hygiene in children is a very important initial measure. The next step will be the individual selection of hygiene products.

Given the manifestation of the pathogenic factors of CF, it is necessary to prescribe toothpastes and mouthwashes with certain active substances. Products contains fluoride, enzymes, antiseptics have the opportunity to remove biofilms. It is also necessary to use bioactive additives on condition of inflammation of periodontal tissues. It is correct to prescribe means contain mineral salts and enzymes for stimulation of salivation in these patients [21, 22].

It is known that fluorides exhibit bacteriostatic and bactericidal effects, reduce the viscosity of saliva due to exposure at oral mucins. The known facts about the direct connection of the level of fluoride and the level of $\operatorname{sIgA}$ in the oral liquid $[21,23]$.

Enzymes in hygienic products (lysozyme, lactoperoxidase, lactoferrin) actively dissolve the organic matrix of microbial biofilm, have antimicrobial, antiviral, bactericidal effects. Numerous studies have shown a decrease of amount of plaque and reduced inflammation of periodontal tissues from the influence of these enzymes [24].

Complex mineral salts in hygiene products provide normalization of metabolic processes and stimulate salivation. Bioactive additives exhibit anti-inflammatory, keratoplastic effects. They stimulate metabolic processes in periodontal tissues and reduce bleeding gums. These are medicinal plant extracts, vitamins and microelements in the composition of dental hygiene products [24].

During professional hygiene it is necessary to use such means and tools that can provide a qualitative cleansing effect and, at the same time, could not damage the enamel of the tooth. There are contraindications to the use of some methods, instruments or apparatus in children with concomitant pathology. The use of air-abrasive systems in professional oral hygiene has a contraindica- 
tion in these patients. Also limited use of professional pastes with a high degree of abrasiveness due to the tendency to osteoporosis in these children [10]. The same reason could limit the appointment of an electric toothbrush for patients with CF.

The aim of the study was to determine the initial level of oral hygiene in children with CF and after 3 months of professional and home-based hygiene measures and to select dental hygiene products that active towards factors that affect plaque in CF patients.

\section{Materials and methods}

To achieve this goal a clinical dental examination of 24 children aged 3-17 years with a confirmed diagnosis of CF were conducted in Kharkiv Regional Children’s Clinical Hospital №1, Kharkiv, Ukraine, during 2016-2018. Oral care education and individual selection of hygiene products and methods and professional oral hygiene were carried out in this group.

Children were not divided by age groups. An assessment of initial oral hygiene and after 3 months was carried out.

The hygienic index OHI-S (J. C. Green, J. R. Wermillion, 1964) was used to determine the state of hygiene of the oral cavity. The criteria for interpreting the index were "good", "satisfactory", "unsatisfactory" and "bad" hygiene.

The study was conducted in accordance with the requirements of the Council of Europe Convention on Human Rights and Biomedicine, the Helsinki Declaration of the World Medical Association and approved by the local ethics committee of the Kharkiv National Medical University (protocol No. 6, from 01.06.2016). All patients signed informed consent for participating in the clinical study.

The data were analyzed using Student's criterions. Statistical analysis of the results was performed using generally accepted statistical methods the calculation of the arithmetic mean (M) and average error $(\mathrm{m})$.

\section{Results}

During the clinical observing, we found a significant prevalence of dense biofilm with enhanced adhesive properties. Children and their parents said that they could not remove all the plaque themselves while was cleaning their teeth (Fig. 1).

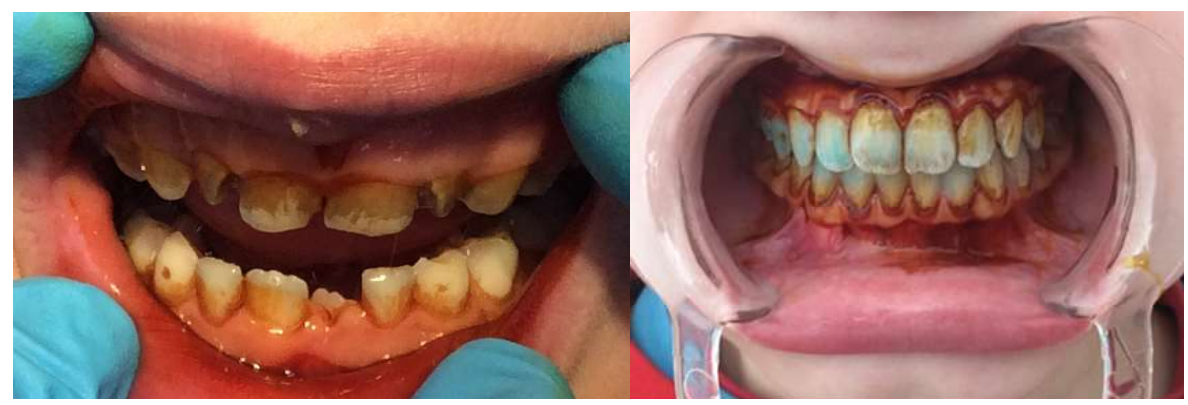

Fig. 1. Dental plaque in children with cystic fibrosis at the first examination

The level of hygiene of the oral cavity was unsatisfactory among patients (OHI-S=2.19 \pm 0.11 ). The index in 4 children (16.7\%) was estimated as "satisfactory" hygiene, in 13 children (54.2\%) as "unsatisfactory" and as "bad" hygiene in 7 (29.1\%) children. "Good" hygiene of the oral cavity was not defined in the group.

The training of hygienic care of the oral cavity and individual selection of hygiene products had been carrying out. We prescribed toothpastes containing xylitol, plant enzymes, phosphorus, magnesium and lysozyme for daily care. In addition, the using of mouthwash, containing calcium lactate, lactoperoxidase, lactoferrin was prescribed.

In the dental office, circular brushes that have little friction and rubber cups were used to remove the plaque. We used abrasive low-dispersion fluoride paste (RDA 27) to clean and to polish the surfaces of the teeth. Then a gel with chlorhexidine and betaine to prevent the formation 
of biofilm on the enamel of teeth and to ensure the water balance of the mucous membrane was prescribed for 7-10 days.

An oral hygiene assessment was performed after 3 months. Hygienic habits and skills obtained after training were tested. The analysis showed the value of the index OHI-S $=1.27 \pm 0.46$ had a significant difference $(\mathrm{p}<0.01)$ in relation to the initial data. Interpretation of the index: in 6 children $(25 \%)$ was "good" hygiene, in 16 children $(66.7 \%)$ - as "satisfactory" and "unsatisfactory" hygiene in $2(8.3 \%)$ children, mostly younger. "Bad" oral hygiene was not registered.

\section{Discussion}

The obtained data are clearly showing that cystic fibrosis patients have different factors that affect caries, gingivitis or another oral pathology. According to known data, it is believed that somatic disease and caused by it secondary pathology affects the health of the oral cavity. Similar trend was found at the presence of enamel defects, dental caries, dental hygiene and plaque in children with CF $[25,26]$.

With insufficient hygiene, the secretion of saliva decreases, the protective mechanisms weaken, the evacuation of bacteria is impaired [27]. Frequent intake of high-calorie carbohydrate food contributes to the formation of an exopolysaccharide matrix on the teeth surfaces. This promotes microbial biofilm formation. In conditions of poor hygiene, the critical mass of microorganisms increases, which is the starting point of pathological processes in the oral cavity [28].

We have found up that individual selection of hygiene products and methods should have performed taking into account the certain changes in the oral cavity's status. The presence of a dense microbial dental biofilm - an important hygiene level factor - requires the use of fluorine-containing agents, enzymes, antiseptics, chlorhexidine and betaine. Inflammation of periodontal tissues requires the inclusion of bioactive additives in this list. It is advisable to use agents containing mineral salts and enzymes to stimulate salivation.

So, CF patients need training and correction of oral hygiene skills, the right pathogenically sound choice of oral hygiene products.

Study limitations. Such studies are not invasive and could be limited by the reluctance of patient-physician collaboration. In addition, the limitations of our study were related to the age of children and their ability to adopt hygiene skills. It is known that some oral hygiene indices cannot be applied in young children. Also, the composition of oral hygiene products for young and older children is different. Thus, we excluded children under 3 years old from the study in order to unify the research design. However, the issue of oral hygiene in the youngest children with cystic fibrosis has not yet been investigated and has a certain scientific interest.

Prospects for further research. Teaching children to brush their teeth can reduce tooth plaque in the short term. Thanks to the data obtained, it becomes necessary to develop individual schemes of prevention of the oral cavity diseases in children with cystic fibrosis, taking into account the age, concomitant pathology, etc.

\section{Conclusions}

This study has shown the low level of oral hygiene in children with CF. These patients rarely pay attention to oral hygiene due to the complicated treatment of CF.

Hygienic education and motivation in CF patients are important starting points for the treatment and prevention of dental diseases and could help them achieve a higher level of oral health knowledge.

Hygiene products for daily care for CF patients should be selected to taking into account the manifestation of the pathogenesis of somatic disease and should consist xylitol, plant enzymes, microelements, immunomodulating and saliva enhancing components. The dentists should use means and methods that are not contraindicate in patients of this category.

It is recommended to monitore the hygiene indices to establish the effectiveness of the measures and necessity for individually therapy correction.

\section{Conflict of interests}

The authors declare that they have no conflicts of interest. 


\section{References}

[1] Abranches, J., Zeng, L., Kajfasz, J. K., Palmer, S. R., Chakraborty, B., Wen, Z. T. et. al. (2018). Biology of Oral Streptococci. Microbiology Spectrum, 6 (5). doi: http://doi.org/10.1128/microbiolspec.gpp3-0042-2018

[2] Ghazal, T. S., Levy, S. M., Childers, N. K., Carter, K. D., Caplan, D. J., Warren, J. J. et. al. (2018). Mutans Streptococci and Dental Caries: A New Statistical Modeling Approach. Caries Research, 52 (3), 246-252. doi: http://doi.org/ $10.1159 / 000486103$

[3] Teles, R. P., Gursky, L. C., Faveri, M., Rosa, E. A., Teles, F. R. F., Feres, M. et. al. (2010). Relationships between subgingival microbiota and GCF biomarkers in generalized aggressive periodontitis. Journal of Clinical Periodontology, 37 (4), 313-323. doi: http://doi.org/10.1111/j.1600-051x.2010.01534.x

[4] Castellani, C., Duff, A. J. A., Bell, S. C., Heijerman, H. G. M., Munck, A., Ratjen, F. et. al. (2018). ECFS best practice guidelines: the 2018 revision. Journal of Cystic Fibrosis, 17 (2), 153-178. doi: http://doi.org/10.1016/j.jcf.2018.02.006

[5] Denga, O., Pyndus, T., Gargin, V., Schneider, S. (2017). Influence of metabolic syndrome on condition of microcirculatory bed of oral cavity. Georgian Medical News, 273, 99-104.

[6] Kovac, I. V., Kravchenko, L. I., Gargin, V. V. (2016). Morphofunctional peculiarities of tissue of oral cavity in chronic recurrent aphthous stomatitis with therapeutical correction. Inter Collegas, 4, 201-205. doi: http://doi.org/10.35339/ ic.3.3.146-149

[7] Kovach, I., Kravchenko, L., Khotimska, Y., Nazaryan, R., Gargin, V. (2017). Influence of ozone therapy on oral tissue in modeling of chronic recurrent aphthous stomatitis. Georgian Medical News, 264, 115-119.

[8] Nazaryan, R., Kryvenko, L. (2017). Salivary oxidative analysis and periodontal status in children with atopy. Interventional Medicine and Applied Science, 9 (4), 199-203. doi: http://doi.org/10.1556/1646.9.2017.32

[9] Nazaryan, R. S., Kryvenko, L. S., Gargin, V. V. (2017). The role of nitric oxide synthase in the modulation of the immune response in atopic disease. The New Armenian Medical Journal, 11 (2), 52-57.

[10] Monroe, E. J., Pierce, D. B., Ingraham, C. R., Johnson, G. E., Shivaram, G. M., Valji, K. (2018). An Interventionalist's Guide to Hemoptysis in Cystic Fibrosis. RadioGraphics, 38 (2), 624-641. doi: http://doi.org/10.1148/rg.2018170122

[11] Avilova, O., Shyian, D., Marakushin, D., Erokhina, V., Gargin, V. (2018). Ultrastructural changes in the organs of the immune system under the influence of xenobiotics. Georgian Medical News, 279, 132-137.

[12] Shmulich, V. K., Uryvayva, M. K., Lupaltsova, O. S., Staruseva, V. V., Rybka, O. S., Shmulich, O. V., Kryvenko, L. S. (2015). Comparative analysis of the role of domestic allergens in atopic dermatitis etiology in children. Inter collegas, 2 (3), 205-211.

[13] Cheng, K., Ashby, D., Smyth, R. L. (2011). Oral steroids for long-term use in cystic fibrosis. Cochrane Database of Systematic Reviews. doi: http://doi.org/10.1002/14651858.cd000407.pub2

[14] Mahmoud, E., Omar, O. (2018). Erosive and cariogenic potential of various pediatric liquid medicaments on primary tooth enamel: A SEM study. Dental and Medical Problems, 55 (3), 247-254. doi: http://doi.org/10.17219/dmp/91539

[15] Rosenfeld, M., Emerson, J., McNamara, S., Joubran, K., Retsch-Bogart, G., Graff, G. R. et. al. (2010). Baseline Characteristics and Factors Associated With Nutritional and Pulmonary Status at Enrollment in the Cystic Fibrosis EPIC Observational Cohort. Pediatric Pulmonology, 45 (9), 934-944. doi: http://doi.org/10.1002/ppul.21279

[16] Norton, L., Page, S., Sheehan, M., Mazurak, V., Brunet-Wood, K., Larsen, B. (2014). Prevalence of Inadequate Vitamin D Status and Associated Factors in Children With Cystic Fibrosis. Nutrition in Clinical Practice, 30 (1), $111-116$. doi: http://doi.org/10.1177/0884533614562839

[17] Zampoli, M. (2018). Cystic fibrosis: What's new in South Africa in 2019. South African Medical Journal, 109 (1), $16-19$. doi: http://doi.org/10.7196/samj.2018.v109i1.13415

[18] Avilova, O., Marakushin, D., Nakonechna, O., Gargin, V. (2018). Microscopic features of the spleen under the influence of laproxides. Georgian Medical News, 163-167.

[19] Igic, M., Mihailovic, D., Kesic, L., Milasin, J., Apostolovic, M., Kostadinovic, L., Janjic, O. T. (2011). Cytomorphometric and clinical investigation of the gingiva before and after low-level laser therapy of gingivitis in children. Lasers in Medical Science, 27 (4), 843-848. doi: http://doi.org/10.1007/s10103-011-0993-z

[20] Fernández-Ferrer, L., Vicente-Ruíz, M., García-Sanz, V., Montiel-Company, J. M., Paredes-Gallardo, V., Almerich-Silla, J. M., Bellot-Arcís, C. (2018). Enamel remineralization therapies for treating postorthodontic white-spot lesions: A systematic review. The Journal of the American Dental Association, 149 (9), 778-786.e2. doi: http://doi.org/10.1016/ j.adaj.2018.05.010

[21] Madlena, M. (2013). Experiences with amine fluoride containing products in the management of dental hard tissues lesions focusing on Hungarian tudies: A review. Acta Medica Academica, 42 (2), 189-197. doi: http://doi.org/10.5644/ ama2006-124.86 
[22] Bress, L. E., Horowitz, A. M., Capobianco, D. M., Fleming, D. E., Kleinman, D. V. (2019). Assessing Dental Hygiene Students' and Community Caregivers' Knowledge of Strategies for Caries Prevention. Journal of Dental Education, 83 (3), 351-358. doi: http://doi.org/10.21815/jde.019.022

[23] Van Ravenhorst, M. B., den Hartog, G., van der Klis, F. R. M., van Rooijen, D. M., Sanders, E. A. M., Berbers, G. A. M. (2018). Induction of salivary antibody levels in Dutch adolescents after immunization with monovalent meningococcal serogroup C or quadrivalent meningococcal serogroup A, C, W and Y conjugate vaccine. PLOS ONE, 13 (4), e0191261. doi: http://doi.org/10.1371/journal.pone.0191261

[24] Kumar, P., Ansari, S. H., Ali, J. (2009). Herbal Remedies for the Treatment of Periodontal Disease - A Patent Review. Recent Patents on Drug Delivery \& Formulation, 3 (3), 221-228. doi: http://doi.org/10.2174/187221109789105603

[25] Abu-Zahra, R., Antos, N., Kump, T., Angelopoulou, M. (2019). Oral health of cystic fibrosis patients at a north american center: A pilot study. Medicina Oral Patología Oral y Cirugia Bucal, 24 (3), e379-e384. doi: http://doi.org/10.4317/ medoral.22756

[26] Peker, S., Kargul, B., Tanboga, I., Tunali-Akbay, T., Yarat, A., Karakoc, F. et. al. (2015). Oral health and related factors in a group of children with cystic fibrosis in Istanbul, Turkey. Nigerian Journal of Clinical Practice, 1, 56-60.

[27] Smyth, A. R., Bell, S. C., Bojcin, S., Bryon, M., Duff, A., Flume, P. Et. al. (2014). European Cystic Fibrosis Society Standards of Care: Best Practice guidelines. Journal of Cystic Fibrosis, 13, S23-S42. doi: http://doi.org/10.1016/j.jcf. 2014.03.010

[28] Cummins, D. (2013). Dental caries: a disease which remains a public health concern in the 21st century - the exploration of a breakthrough technology for caries prevention. The Journal of Clinical Dentistry, 24, 1-14. 